\title{
中国种子植物物种多样性及其分布格局
}

\author{
应俊生 \\ (中国科学院植物研究所系统与进化植物学开放研究实验室, 北京 100093)
}

摘要: 缤纷的中国植物区系包含着大量的特有种, 这使中国成为北半球最富植物多样性的国家。其原因一是土地 面积辽阔, 植物演化历史时间悠久, 气候相对稳定。二是中国具有连续完整的热带、亚热带、温带和寒带的植被类 型。三是伴随地质构造上的活跃, 中国广大陆地受到了强烈的深切和抬升, 导致生境复杂多样, 使中国成为一个重 要的植物物种保存中心、形成中心和进化中心。中国植物多样性的分布是很不均匀的, 主要集中分布于中南部, 约 在 $20^{\circ} \sim 35^{\circ} \mathrm{N}$ 之间。在该范围内, 我们确定了 3 个植物多样性热点地区: 横断山脉地区、华中地区和岭南地区, 它 们的植物多样性和特有性程度都很高, 其中横断山脉地区尤为突出。

关键词：植物多样性，分布格局，热点地区，中国

中图分类号:Q15文献标识码：A 文章编号 : 1005-0094(2001)04-0393-06

\section{Species diversity and distribution pattern of seed plants in China}

\section{YING Tsun-Shen}

Laboratory of Systematic and Evolutionary Botany , Institute of Botany , Chinese Academy of Sciences , Beijing 100093

\begin{abstract}
China has an extremely diverse flora with very high levels of endemism that has given China first place in the Northern Hemisphere in floristic richness. A combination of three reasons explains the floristic richness of China. First, the large area, long time for the organisms to evolve and climatic stability of China has made the country an important region of plant diversity in the Northern Hemisphere. Second , China is unique in being the country in the world that includes a region with vegetational continuity between tropical, subtropical, temperate, and boreal forests. Third, the tectonically active, highly dissected and elevated geography of China has made the country an important center of surrival , speciation and evolution. The diversity of plant is not uniformly distributed over China, but is concentrated in the south-central part of China which reaches from ca. $20^{\circ} 0^{\prime}$ to $35^{\circ} 0^{\prime} \mathrm{N}$. The diversity and levels of endemism within three localized hot-spots in south-central China, the Hengduan range, the C. China and the Lingnan region, are notable in comparison with other regions. The Mt. Hengduan flora in particular is the richest of the three Chinese Hot-spots. However, of all the Hot-spots, the Hengduan Range. C. China and Lingnan region are most in need of conservation attention.
\end{abstract}

Key words : plant diversity, distribution pattern, hot-spot, China

\section{1 中国是北半球植物多样性最丰富的地区}

板块构造的证据已经进一步证实了大陆不是固 定不动的, 而是在不断地移动。古生代末期 地球的 地表还是一个超级大陆块, 常称泛古大陆。到了中 生代早期, 泛古大陆裂成两块: 居北的劳亚大陆和居 南的冈瓦纳大陆。到了侏罗纪或稍早时期, 北半球 各大陆块仍然联接成一个大陆块。这个时期, 整个
北半球的植被都很相似，在东亚和北美大约有 $40 \%$ 的种是一致的 (Axelrod et al. 1998)。侏罗纪时期 的植被开始呈纬向分带,一些热带偋类植物特别是 马通層科 (Matoniaceae) 、双扇偋科 (Dipteridaceae) 和 Marattiaceae 局限分布于低、中纬度地区, 显示湿 热生境条件。北方则出现大量松杉类植物和银杏类 植物，热带蕨类和苏铁类植物却很少（Vakhrameev， 
$1964,1991)$ 。近年在中国辽宁省西部北票县发现世 界上最早的 (1 亿4500 万年前) 被子植物大化石辽 宁古果 (Archaefructus liaoningensis) ( Sun et al. ， 1998 )。到了早白严纪, 在低、中纬度地带出现一些 现代的科, 如 Winteraceae 和蜡梅科 (Calycanthaceae) 等。这些早期被子植物区系向两极散布, 大约到 晚阿尔比期和赛诺曼期到达较高纬度地带 (Axelrod ,1959)。

第三纪初，约在 6500 万年前，中国、欧洲和北美 的现代松杉类植物和被子植物已经广布于欧亚和北 美, 而且, 直到 1500 万前中新世中期, 这些地区的植 物区系十分类似,物种丰富度也都相当。

第四纪时期虽然很短促, 但由于在此期间冰期 发生，许多地方产生冰川作用，对欧亚和北美的自然 界都有不同程度的影响。欧洲大陆多东西走向的山 脉, 这里冰期前后的植物变化较大; 北美山脉呈南北 走向，植物迁移受阻较少，所以冰期前后的植物类群 差异小于欧洲; 中国没有大规模的冰川地形复杂多 样，植物类群可以说没有发生过重大的改变，冰川对 植物的作用相对小于欧美。因此，现代全球248000 种高等植物中，中国约占 $1 / 8$ 。若与欧洲、北美的美 国作一比较: 欧洲土地面积约 990 万 $\mathrm{km}^{2}$,约有 11 500 种; 美国土地面积约 940 万 $\mathrm{km}^{2}$,约有 18000 种, 而中国约 960 万 $\mathrm{km}^{2}$,却有近 30000 种植物。这 三个地区的面积大致相当，但物种丰富度差异较大， 其比率大致为 1:2:3(Axelrod et al.,1998) , 足见 中国是北半球植物多样性最丰富的地区。

\section{2 中国具有北半球最丰富的种子植物物种 多样性的原因}

全球种子植物约有 220529 种 (Wilson ,1992)。 中国种子植物约有 27268 种，隶属于 3200 属 337 科 (李锡文，1996，按哈钦松系统概念），约占全球总种 数的 $12.36 \%$ 。这里具有极丰富的物种多样性的原 因在于：

\section{1 面积、时间和稳定的气候}

中国的土地面积约 960 万 $\mathrm{km}^{2}$ ，几乎占全球土 地面积的 $1 / 15$, 仅次于前苏联和加拿大, 是世界第 三位土地面积最大的国家。有人认为, 面积每增加 10 倍,物种数就增加 1 倍。这是因为较大的面积可 能让有些物种能找到更多的栖境, 为多样性演化达 到较高程度提供各种不同的舞台。在自然条件基本
一致的情况下, 面积对植物多样性的增加具有十分 重要的意义。其次是时间, 即植物演化所需的时间, 要有足够的时间让植物同生过程完成, 竞争程度缓 和, 自然灭绝率降低, 物种得以众聚, 才能出现大容 量的生物群。我国贵州凤冈发现的 Pinnatiramosus qianensis 很可能是目前世界上最早的陆地维管植物 (蔡重阳等,1995)，我国辽宁西部发现的辽宁古果 是迄今世界上最早的被子植物大化石 ( Sun et al. , 1998 ）,在我国一些区域具有足够的植物演化时间。 在植物演化过程中, 有了大面积区域和足够的演化 时间, 还必须具备能创建生物多样性程度较高的另 一先决条件, 这就是要具有稳定的气候。据古气候 分析, 我国在地质史上潮湿热带、亚热带的气候分布 是相当广阔的, 进入第四纪之前, 形成了大量喜湿热 植物类群。第四纪古气候有多次波动, 较大的波动 至少有 5 次, 较小的约有 9 次。5 次较大的气温下 降时,由于欧洲、北美大陆冰川广泛发育，几乎全部 被大陆冰川所覆盖。中国第四纪冰川, 由于是山岳 冰川, 加之地形复杂, 大部分地区未被冰川所覆盖, 仍有保留湿热的气候环境。到了全新世时期, 气候 更趋湿热，尤其华南地区长期保持湿热的环境条件， 对中生代和新生代的植物进化起着重要的作用。

\section{2 具有热带至寒温带连续完整的植被类型}

中国是北半球乃至全世界唯一具有热带、亚热 带至寒温带连续完整的各类植被类型的地区。阿根 廷生态学家拉波波特的法则认为:当在北美洲往南 走或从温带南美洲往北走时,愈近赤道, 各个物种的 分布范围愈小 ( Rapoport, 1975)。同样,山区物种的 垂直分布愈近赤道也愈窄缩。因此, 在等量的空间 里, 热带比温带可容纳更多的物种。据估计, 热带雨 林的面积虽然只占陆地面积的 $6 \%$, 却蕴藏了地球 上一半以上的生物物种（Wilson,1992) , 中国热带季 雨林、雨林区域虽已是热带北缘, 面积不到全国面积 的 $1 / 10$, 但约占全国种子植物总种数的一半以上。 华南土地面积约 41.4 万 $\mathrm{km}^{2}$, 约有种子植物 7500 种, 其中特有种 4494 种。而广西南部热带地区, 面 积只有约 0.4 万 $\mathrm{km}^{2}$,却约有种子植物 4472 种, 其 中特有种 2,054 种 ${ }^{(1)}$ 。

各类植被类型的连续性也为中国保存大量物种 提供了优越条件。中国几乎拥有温带的全部木本 
属, 尤其是华中地区是世界上落叶木本植物最丰富 的地区。中国已知新生代植物化石约 220 多属, 其 中很多属至今仍在我国广泛分布，如大家熟知的桦 木属 (Betula)、鹅耳枥属(Carpinus)、山楂属 (Crataegus)、白腊树属 (Fraxinus) 和械属 (Acer) 等。

2.3 地质历史复杂, 强烈的深切与抬升导致地理环 境复杂多样

在生物多样性的形成和发展过程中, 海陆的生 成和变迁,气候的急剧变化, 高山或高原的大规模隆 起，以及区域性生态环境的复杂多样等因素，都会直 接或间接地影响或控制着植物的形成、分布、迁移、 演化，以至灭绝或保存。下古生代的加里东运动使 陆地上升，完整的中国陆台分裂; 古生代 (泥盆纪 二叠纪) 的海西运动, 中国东北、西北地区的主要 山系和秦岭等形成，中国陆台与西伯利亚陆台相连 接，天山与中亚高山高原相通连 ;至中生代侏罗纪一 新生代前的燕山运动期间，形成了唐古拉山、喀喇昆 仑山和横断山脉, 这时, 我国山脉基本形成。至第三 纪中一晚期的喜马拉雅运动, 喜马拉雅山脉和台湾 山脉形成, 青藏高原隆起, 古地中海消失, 使欧亚大 陆连成一片。这时期印度板块与欧亚大陆碰撞联 结。在中国这个地质构造活动性极强的古老大陆不 断演化发展过程中, 强烈的深切与抬升铸造了中国 现代地势和复杂多样的地理环境，创造了生物多样 性特丰产地的优越条件。

上述三个方面的情况，不仅使中国成为北半球 生物多样性最为丰富的国家, 而且使中国成为一个 重要的物种保存中心以及物种形成和进化中心 (Axelrod et al. ,1998)。

3 中国种子植物物种多样性的分布格局及 其特有性

中国种子植物的现代地理分布主要受制于地形 条件所引起的水、热分配的差异。总体看来，绝大部 分种类分布于东南半壁。若将东北黑龙江爱辉县和 西藏东南部的墨脱县作为两点, 再将两点连成一线 (见图 1 中 $\mathrm{AB}$ 连线), 此线以西的西藏 (约 5300 种)、新疆(约 2500 种)、青海 (约 2662 种)、内蒙古 北部和宁夏北部 (约 1500 种) 和甘肃北部 (约 1000 种）植物种类约有 13000 种, 其中西藏的植物种类 最丰富, 含本地的特有种 955 种，约占 $18 \%$ 。若按 此百分比计算, 这些地区约有本地特有种 2300
2500 种, 其余 10000 多种植物与此线以东地区共有 或与其邻近地区共有。可见中国全部种类的 $90 \%$ 出现于此线以东地区。这表明青藏高原区和蒙新高 原区的高寒环境条件和干旱环境条件，均不利于植 物物种多样性的发展。而东南半壁的广大地区受季 风的影响，气候湿热,地形多变,蕴藏着我国种子植 物的绝大多数物种。图 1 中, 上行数字表示该地区 的科一属一种数目（李锡文，李捷, 1993; 祁承经等, 1995 ; 吴征镒主编,1983 1987; 刘昉勋等, 1995;王 荷生等, 1995; 傅沛云等,1995)，示其物种丰富程度； 中行示其特有种 (本地特有种一中国特有种);下行 示特有种在总种数中百分比和土地面积。从图 1 我 们可以看出 :

(1) 我国东南半壁的种子植物物种丰富度及其 特有性程度, 大体上由北往南递增。符合拉波波特 法则。

(2) 我国种子植物物种最丰富和特有性程度最 高的地区主要集中于 $20^{\circ} \sim 35^{\circ} \mathrm{N}$ 之间的亚热带常 绿阔叶林区域，相当于植物区系分区上的中国一日 本森林植物亚区和中国一喜马拉雅森林植物亚区。

(3) 横断山脉地区, 不论是植物物种丰富程度 还是特有性程度都是全国最高的。其次是岭南地区 和华中地区。这三个地区的自然条件和植物区系背 景具有明显的差异。

横断山脉地区北起甘肃西南部和青海东南部， 经四川西部和西藏东至东南部, 直至云南西北部 （李锡文，李捷，1993），地跨我国一级和二级阶地， 位于世界上最高最年轻的青藏高原东南部外围, 地 质构造上十分活跃的地区。总面积约为 50 万 $\mathrm{km}^{2}$ 。 境内怒江、澜沧江、金沙江及其间岭呈南北向; 重峦 叠障, 谷深坡陡, 山势极为雄伟。冰川进退导致气候 带多次上下位移,生境多样, 利于促进植物的分化。 这里具备热带、亚热带至高山寒带各类植被类型, 垂 直分带明显。种子植物区系基本上是温带性质, 但 同时又有不少热带、亚热带成分存在。一些北温带 属如杜鹃花属 (Rhododendron)、报春花属 (Primu$l a) 、$ 龙胆属 (Gentiana)、马先蒿属 (Pedicularis) 和鸟 头属 $($ Aconitum $)$ 等在这里得以高度分化与特化。这 里的种系分化程度即平均每属所含物种数为 6.08 , 明显高于岭南地区和华中地区的 5.22 和 5.00 。表 明这里具有较高的生境多样性。横断山脉地区也是 世界上高山植物区系最丰富的区域 (李锡文, 李捷， 


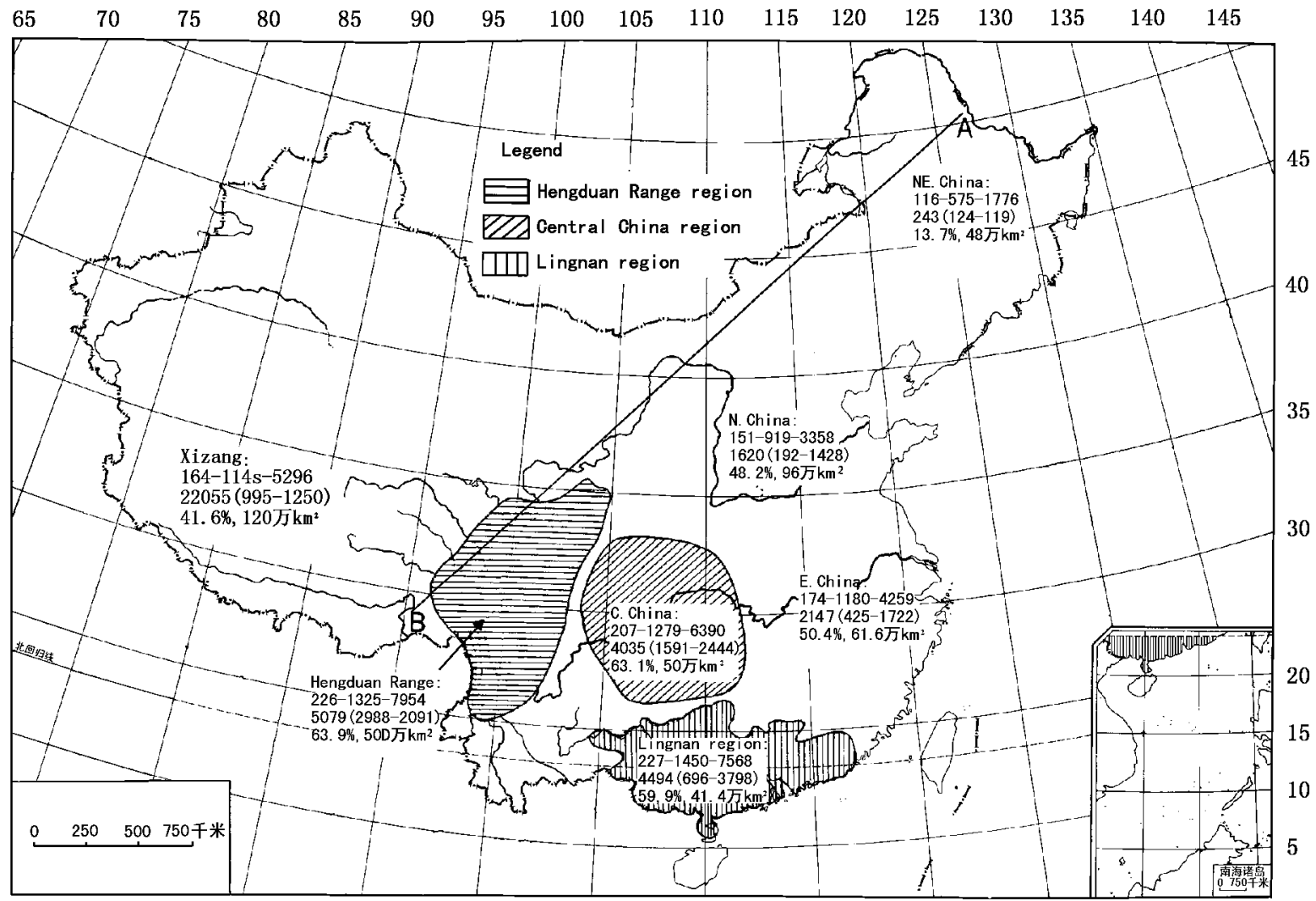

图 1 中国种子植物物种多样性分布格局及热点地区

Fig. 1 Distribution pattern and hot-spots of speceis diversity of seed plants in China

Notes $:$ upper line $=$ number of family - number of genera - number of species in the region $;$ Middle line $=$ total endemic species ( number of the region's endemic species - number of the country's endemic species) ; Lower line = percentage of the region's total species, total area of the region.

1993 ;吴征镒,王荷生,1983)。

华中地区则不同，较横断山区偏东，处于我国第 二台阶和第三台阶的过渡地带, 全境地理位置约为 $25^{\circ} 47^{\prime} \sim 33^{\circ} 20^{\prime} \mathrm{N}, 103^{\circ} 30^{\prime} \sim 111^{\circ} 50^{\prime} \mathrm{E}$, 行政区域包 括陕(南)、甘(东南)、鄂(西)、湘 (西)、川(东)、黔 (东、北)、滇 (东北)、桂 (东北) 等省。总面积约为 50 万 $\mathrm{km}^{2}$ (祁承经等, 1995 )。境内主要有大巴山、 巫山、大娄山、武陵山等。长江由东到西贯穿其中， 河流及其间岭常向四方作星芒状放射,重峦叠障, 山 势雄伟。本区地貌具有山高、坡陡、谷深等特点, 四 川盆地和汉水盆地致使境内地形更趋多样复杂。秦 巴山地绵亘华中之北,成为阻挡北部空气入侵的屏 障。加之境内地形复杂，川东、鄂西等地区“避难 所” 广泛存在, 因此, 这里保存的第三纪植物最具丰 富性和完整性, 也是世界上落叶乔、灌木植物最多的
地区。这里不仅植物种类十分丰富，约有 6390 种， 其中中国特有种在总种数中所占比例高达 $63.1 \%$, 而且中国特有属约有 92 属, 占全国总特有属数的 $37.9 \%$,这些特有属主要集中分布于境内的川东一 鄂西地区, 形成中国三个特有属分布中心之一。因 此, 华中地区是中国植物区系的最典型和最集中的 代表。

岭南地区在行政区划上主要包括广东和广西， 地处欧亚大陆东南部, 较前两地区偏东、偏南, 已入 我国第三阶地, 位于 $20^{\circ} 29^{\prime} \sim 25^{\circ} 31^{\prime} \mathrm{N}, 104^{\circ} 29^{\prime} \sim$ $117^{\circ} 11^{\prime} \mathrm{E}$ 。北回归线横贯中部, 为热带一亚热带的 过渡地区。总面积约 41.4 万 $\mathrm{km}^{2}$ 。三迭纪末期,印 支运动发生, 岭南地区升出海面, 成为陆地, 长期保 持湿热的气候环境, 对中生代和新生代的植物进化 起着重要的作用，决定了该地区现代的植物分布和 
表 1 北半球的热点地区

Table 1 Hot-spots of Northern Hemisphere

\begin{tabular}{lrrr}
\hline \multicolumn{1}{c}{$\begin{array}{c}\text { 热点地区 } \\
\text { Hot-spot }\end{array}$} & $\begin{array}{c}\text { 面 积 } \\
\text { Area }\left(\mathrm{km}^{2}\right)\end{array}$ & $\begin{array}{c}\text { 植物物种 } \\
\text { Plant species }\end{array}$ & $\begin{array}{c}\text { 特有种(占全部种的百分比) } \\
\text { Endemic species (Percentage } \\
\text { of all plant species) }\end{array}$ \\
\hline 美国加州植物区系省 California Floristic Province & 324000 & 4426 & $2125(48.0 \%)$ \\
中美地区 Mesoamerica & 1155000 & 24000 & $5000(20.8 \%)$ \\
加勒比地区 Caribbean & 263500 & 12000 & $7000(58.3 \%)$ \\
地中海盆地 Mediterranean Basin & 2362000 & 25000 & $13000(52 \%)$ \\
高加索地区 Caucasus & 500000 & 6300 & $1600(25.4 \%)$ \\
西非林区 Western African Forests & 1265000 & 9000 & $2250(25 \%)$ \\
印度西高止山脉和斯里兰卡 Western Ghats/Sri Lanka & 182500 & 4780 & $2180(45.6 \%)$ \\
菲律宾地区 Philippines & 300800 & 7260 & $5832(76.5 \%)$ \\
印度一缅甸地区 Indo-Burma & 2060000 & 13500 & $7000(51.9 \%)$ \\
中国横断山脉地区 Chinese Hengduan Mts. & 500000 & 7954 & $5079(63.9 \%)$ \\
华中地区 Central China region & 500000 & 6390 & $4035(63.1 \%)$ \\
中国岭南地区 Chinese Lingnan region & 41400 & 7568 & $4494(59.4 \%)$ \\
\hline
\end{tabular}
基本资料来源 :李锡文 ,1993 ;苏志尧,1993 ;廖文波,1992;Myers ,1998、1990;Myers et al. 2000。

Sources : Li Xi-Wen \& Li Jie , 1993 ; Su Zhi-Yao , 1993 ; Liao Wen-Bo , 1992 ; Myers , 1998 ,1990 ; Myers et al. , 2000.

植物区系性质和特点。山毛榉科的栲属( Castanopsis)、柯属( Lithocarpus) 和常绿栋类以及樟科、山茶 科、木兰科和金梅科等组成岭南地区植物区系的表 征科 ${ }^{\circledR}$ 。全地区总体地势北高南低, 变化多样, 我国 第三大江珠江纵横交错。北部湘莽山主峰石坑崆 (海拔 $1902 \mathrm{~m}$ ) 是广东最高峰,广西东北的苗儿山 (海拔 $2142 \mathrm{~m}$ ) 为该地区的最高峰。本区尤其西部 地貌的一个主要特征是岩溶地形广泛发育, 是我国 面积最大、发育最完备、种类繁多的地貌类型, 在这 里发育着独特的石灰岩植物区系。岭南地区与华中 地区一样，也是中国一日本植物区系的核心部分，但 具有亚热带向热带过渡的特点, 深受热带马来西亚 区系的深刻影响，尽管缺乏典型的热带科如龙脑香 科、肉豆寇科等, 但这里仍然是热带分布的科、属占 优势。在植物区系物种丰富程度上远较华中地区丰 富，约有 7568 种，中国特有种在总种数中所占比例 高达 $59.9 \%$ (1) 。岭南地区南濒南海, 因而具有一定 数量的热带海岸植物, 如红树科的红海榄 (Rhizophora stylosa)、秋茄 (Kandelia candel) 和木榄 (Bruguiera gymnorrhiza)、苦槛蓝科的苦槛蓝 (Myoporum bontioides) 以及草海桐科等, 这是不同于前述二地区的 另一重要特点。

植物多样性研究中的 热点 (hot-spot)"一词是 由 Myers (1988) 最先提出来的, 它是指物种高度丰 富、特有种高度集中又面临极度受威胁的地区, $\mathrm{My}$ ers (1988) 起初确定了 10 个热点地区,几乎全部处 于热带雨林。后来, Myers (1990) 增加了 4 个热带雨 林地区的热点地区和 4 个地中海气候型地区的热点 地区，包括南非开普顿地区( Cape region) (Cowling
\& Hilton-Taylor, 1994)。10 年后, Myers et al. (2000) 又增加了 7 个热点地区, 至此, 全球共有 25 个热点地区, 即北半球 10 个和南半球 15 个热点地 区。北半球热点地区中包括 中国中南部热点地 区”，但作者对该热点地区未作具体论述，图 1 中的 热点地区的地理位置与实际情况也不尽相符。因此 有必要根据中国植物多样性的实际情况进行具体分 析。南非开普顿地区的 8550 种植物中，约有 $73 \%$ 即 6252 种为特有种 (Goldblatt,1978), , 被认为全球 热点地区中最热的地区 (Myers, 1990)。然而, 在 Myers et al. (2000) 发表的论文中列出的全球 8 个最 热的热点地区, 其中却没有南非开普顿热点地区。 在同一地区物种数和特有性程度并无明显变化的情 况下, 会有如此不同的结果, 主要由于采用的标准很 不一致所造成的。因此, 采用一致的标准十分重要。 若以物种高度丰富和特有种高度集中为首要标准， 我们可以从表 1 中清楚地看出:横断山脉地区、华中 地区和岭南地区都有较高的植物物种多样性, 植物 的特有性程度接近或超过 $60 \%$,高于除菲律宾地区 以外的所有北半球热点地区, 包括加勒比地区、印度 西高止山脉/斯里兰卡地区和印度一缅甸地区 3 个 世界最热的热点地区 (Myers et al. ,2000)。再联系 到前面对横断山脉地区、华中地区和岭南地区在自 然条件、植物区系和植被等方面的分析情况，似可将 这三个地区视为中国植物多样性研究中的热点地 区。

(1) 廖文波, 1992. 广东亚热带植物区系研究. 中山大学博士学位论文 (2)薛跃规, 1995. 广西热带植物区系研究. 中山大学博士学位论文 (3)苏志尧, 1993. 广西植物区系的研究. 中山大学博士学位论文 


\section{参考文献}

蔡重阳, 欧阳舒, 王怿, 1995. 志留纪植物群, 见: 李星学 (主 编), 中国地质时期植物群. 广东科技出版社, $3 \sim 21$

傅沛云, 李冀云, 曹伟, 1995. 东北植物区系地区种子植物区 系研究. 云南植物研究 (增刊 VII) : 11 21

李锡文, 李捷, 1993. 横断山脉地区种子植物区系的初步研 究. 云南植物研究, 15(3): 217 231

李锡文, 1996. 中国种子植物区系统计分析. 云南植物研究, 18(4) : $363 \sim 384$

刘尚武( 主编), 1997～1999. 青海植物志 (1～4 卷). 青海人 民出版社

刘昉勋, 刘守炉, 杨志斌, 1995. 华东地区种子植物区系研究. 云南植物研究( 增刊 VII ) : 93 110

马毓泉 (主编), 1977 1985. 内蒙古植物志 (1 8 卷). 内蒙古 人民出版社

祁承经, 喻勋林, 肖育檀, 1995. 华中植物区种子植物区系的 研究. 云南植物研究 (增刊 VII) : 55 92

吴征镒, 王荷生, 1983. 中国自然地理一植物地理 (上册). 北 京: 科学出版社

吴征镒 (主编), 1983 1987. 西藏植物志 (1 5 卷). 北京: 科 学出版社

王荷生, 张镱锂, 黄劲松, 1995. 华北地区种子植物区系研究. 云南植物研究( 增刊VII) : 32 54

Axelrod D I, 1959. Pole-ward migration of early angiosperm flora. Science, 130: $203 \sim 207$

Axelrod D I, Al-Shehbaz I and Raven P H, 1998. History of the modern flora of China. In: Zhang A, Wu S (eds.), Floristic Characteristics and Diversity of East Asian Plants. Beijing: CHEP and Springer-Verlag Press, $43 \sim 55$
Cowling R M and Hilton-Taylor C, 1994. Pattern of plant diversity and endemism in Southern Africa: an overview. In: Huntley B J (ed.), Botanical Diversity in Southern Africa. Cape Town: Oxford University Press, $31 \sim 52$

Goldblatt P, 1978. An analysis of the flora of Southern Africa: its characteristics, relationships and origins. Annals of Missouri Botanical Garden, 65: $369 \sim 436$

Myers N, 1988. Threatened biotes: "hotspots" in tropical forests. The Environmentalist, 8: $1 \sim 20$

Myers N, 1990. The biodiversity challenge: expended hot-spots analysis. The Environmentalist, 10: $243 \sim 255$

Myers N, Mittermeier R A, Mittermeier C G, da Fonseca G A B and Kent J, 2000. Biodiversity hotspots for conservation priorities. Nature, 403: $853 \sim 858$

Rapoport E H, 1975. Areography: geographical strategies of species. Translated by B. Drausal. Pergamon Press, 269

Sun G, Dilcher D L, Zheng S L and Zhou Z K, 1998. In search of the first flower: a Jurassic angiosperm, Archaefructus, from Northeast China. Science, 282: $1692 \sim 1695$

Vakhrameev V A, 1964. Jurassic and Early Cretaceous Floras of Eurasia and Contemporary Paleofloristic Provinces. Moscow, 261 pp. (In Russian)

Vakhrameev V A, 1991. Jurassic and Cretaceaus Floras and Climates of the Earth. Cambridge: Cambridge University Press, 318

Wilson E O, 1992. The Diversity of Life. The Belknap Press of Harvard University Press, Cambridge, Mass. 424

(责任编辑：时意专) 